\title{
An epidemiological cross-sectional study to assess the level of stress and its association with hypertension in young adult population of age group 20 to 40 years in an urban slum of Mumbai, Maharashtra, India
}

\author{
Amrin Y. Tadvi*, Janardhan R. Bandi
}

\begin{abstract}
Department of Community Medicine, Topiwala National Medical College and BYL Nair Ch. Hospital, Mumbai, Maharashtra, India
\end{abstract}

Received: 26 November 2016

Accepted: 23 December 2016

*Correspondence:

Dr. Amrin Y. Tadvi,

E-mail: dramrin10@yahoo.com

Copyright: () the author(s), publisher and licensee Medip Academy. This is an open-access article distributed under the terms of the Creative Commons Attribution Non-Commercial License, which permits unrestricted non-commercial use, distribution, and reproduction in any medium, provided the original work is properly cited.

\begin{abstract}
Background: Hypertension is a growing health concern in Asia and some tend to associate their hypertension to psychosocial stress. However, data on assessment of stress and its relationship with hypertension are rare. The objectives were to assess the level of stress and its relation with hypertension amongst the young population of 20 to 40 years of an urban slum of Mumbai.

Methods: A cross sectional community based study of 450 participants in the age group of 20 to 40 years using systematic sampling technique with a random start. Data was collected using a questionnaire-cum-examination form that was devised relevant to the study. Blood pressure was assessed using shypnomanometer and stress was assessed using stress questionnaire score. Blood pressure <139/89 mm Hg (normal) \& >140/90 mm of Hg (hypertension).

Results: Amongst 450 participants, $41(9.1 \%)$ participants had minimal stress, $164(36.4 \%)$ had mild stress, 142 (31.6\%) had moderate stress and 103 (22.9\%) had severe stress. Out of 450 participants $73(16.2 \%)$ had blood pressure $>140 / 90 \mathrm{~mm}$ of $\mathrm{Hg}$. Association between severe stress and hypertension was found to be statistical significant.

Conclusions: Severe stress is associated with development of hypertension. Special attention should be given to increase the awareness about stress, its related complications and prevention and control measures.
\end{abstract}

Keywords: Stress, Hypertension, Young adult, Urban slum

\section{INTRODUCTION}

Stress is among the psychological variable that has long been listed among the potential and important risk factors of hypertension and coronary heart disease. Stress has been defined as a process in which environmental demands exceed the adaptive capacity of an organism. This can result in psychological and biological changes that may place persons at risk of disease. ${ }^{1}$ There is large variability of exposure and outcomes in terms of stresses and the subsequent effects. Production of stress hormones, for example cortisol, may be triggered by normal physiological activities in humans. This may help prepare the individual sensing or involved in a stressful situation. However, prolonged activation of stress hormones can be harmful. The mechanisms underlying the association between psychosocial stress and hypertension can be divided into behavioural and pathophysiological mechanisms. The former contributes to adverse health behaviours such as physical inactivity, 
poor diet and smoking, whilst the latter involves neuroendocrine activation mediated by the hypothalamopituitary-adrenal (HPA) system. ${ }^{1,2}$

Several studies have supported these underlying mechanisms which may lead to sustained elevated blood pressure, but others do not. ${ }^{3}$ Furthermore, acute stressful events have no consistent association with hypertension. Chronic stress on the other hand, particularly the nonadaptive response to stress, have been reported as more likely the cause of sustained elevation of blood pressure. ${ }^{4}$

\section{METHODS}

\section{Study protocol}

A community based cross-sectional study was carried out among 450 people who are residing in the field practice area (Shivaji Nagar urban health centre) of the Topiwala National Medical College \& B. Y. L. Nair Hospital, Mumbai during the period of July 2014 to June 2015. The ethics committee of the institute approved the study.

\section{Study area}

The study was carried out in an urban slum community which is a resettlement colony on the outskirts of Mumbai and having approximate population of 80000 . This urban slum is the field practice area under the Department of Community Medicine of Topiwala National Medical College, Mumbai. The urban slum consists of total 50 plots. Each plot has A to T line. Each line has 9 houses. The houses in each row face the opposite row forming a pair.

\section{Sample size calculation}

Sample size was calculated considering the prevalence of hypertension in urban slum to be $47.9 \% .^{4}$ And by using the formula: $\mathrm{n}=4 \mathrm{pq} / \mathrm{L}^{2}$, Where $\mathrm{n}=$ sample size, $\mathrm{p}=$ prevalence of hypertension $=47.9 \%, \mathrm{q}=100-47.9=$ 52.1. L=admissible error $(10 \%$ of $\mathrm{p})=10 / 100 \times 47.9=$ 4.79 Now putting values in the formula: $n=4 \times 47.9 \times$ $52.1 / 4.79 \times 4.79=9982.36 / 22.9441=435.07$

So, calculated minimum sample size was around 435 which were extended to 450 . Hence sample size was 450 .

The sample size of 450 was divided among 50 plots equally $-450 / 50=9$, thus total 9 participants of 20 to 40 years (according to the inclusion criteria) were selected from each plot for the study. As there were 180 houses in each plot, 9 participants fulfilling the inclusion criteria were selected by Systematic sampling technique with a random start (In each plot every first house was selected by simple random sampling method). Every $20^{\text {th }}$ house was selected for the study till the sample size of 9 was met from each plot $(180 / 9=20)$. When any house was found locked or inclusion criteria not fulfilled then next house was targeted. Also when more than one sample was found in the same house then all of them were included in the study. And as soon as the target of 9 samples from 1 plot was completed other plot was targeted.

\section{Selection criteria}

The beneficiaries meeting the following inclusion criteria were selected:

- Individuals residing in the houses as randomly selected by the above method.

- Individuals of age between 20-40 years.

- Individuals of either sex.

\section{Data collection}

A pre-designed questionnaire was used to collect necessary information such as socio demographic profile, addictions, stress, blood pressure and general examination was the tool of data collection. Informed consent was obtained verbally from all the participants after explaining the purpose of the study and promise was made about anonymity, and that social and economic information collected about them was to be kept confidential.

\section{Operational definitions}

Examination of blood pressure: The procedure of examination of blood pressure was completely explained to relive anxiety and apprehension. Blood pressure was measured by mercury sphygmomanometer using appropriate sized cuff by auscultatory method in sitting position. ${ }^{[4]}$ Three readings were recorded 3 to 5 minutes apart and lowest reading was taken as the final reading and classified as,

Normal blood pressure $=<120 / 80 \mathrm{~mm} \mathrm{Hg}$

Pre-hypertension $=120 / 80$ to $139 / 90 \mathrm{~mm} \mathrm{Hg}$

Hypertension Stage $1=140 / 90$ to $159 / 99 \mathrm{~mm} \mathrm{Hg}$

Hypertension Stage $2=\geq 160 / 100 \mathrm{~mm} \mathrm{Hg}$

\section{Stress score calculation}

The stress level was assessed in the study subjects using stress questionnaire. ${ }^{6}$ The response to each of the question was graded as 0,2 and 3 . The responses of all questions were summed as total score and were grouped as follows.

Table 1: Stress score calculation.

\begin{tabular}{|ll|}
\hline Total score & Level of stress \\
\hline $0-8$ & No or minimal stress \\
\hline $9-14$ & Mild stress \\
\hline $15-21$ & Moderate stress \\
\hline $22-30$ & Severe stress \\
\hline
\end{tabular}




\section{Statistical analysis}

The statistical analysis was performed using SPSS software (version 17.0). All values are expressed in the form of percentages, mean and standard deviation and the chi-square test was applied wherever necessary. Statistical significance was set at $\mathrm{P} \leq 0.05$.

\section{RESULTS}

As seen from Table 2 that, amongst 450 study subjects, $309(68.7 \%)$ were female and $141(31.3 \%)$ were male.

Table 2: Demographic profile of study subjects.

\begin{tabular}{|llll|}
\hline \multicolumn{2}{l}{$\begin{array}{l}\text { Demographic } \\
\text { profile }\end{array}$} & $\begin{array}{l}\text { Frequency } \\
(\mathbf{n = 4 5 0})\end{array}$ & Percentage \\
\hline \multirow{2}{*}{ Gender } & Female & 309 & 68.7 \\
\cline { 2 - 4 } & Male & 141 & 31.3 \\
\hline
\end{tabular}

It was seen from Table 3 that, amongst 450 participants, $73(16.2 \%)$ participants was hypertensive and $377(83.8 \%)$ participants were not hypertensive. Among 450 participants, $377(83.8 \%)$ participants had blood pressure <139/89 mm Hg, 73 (16.2\%) participants had blood pressure $>140 / 90 \mathrm{~mm} \mathrm{Hg}$.

Table 3: Distribution of blood pressure in the study population.

\begin{tabular}{|lll|}
\hline Blood pressure & $\begin{array}{l}\text { Frequency } \\
(\mathbf{n = 4 5 0 )}\end{array}$ & Percentage \\
\hline Normal & 322 & 71.6 \\
\hline Pre hypertension & 55 & 12.2 \\
\hline Hypertension stage I & 64 & 14.2 \\
\hline Hypertension stage II & 9 & 2.0 \\
\hline Total & 450 & 100 \\
\hline
\end{tabular}

As seen from Table 4 that, out of the 450 participants, 41 (9.1\%) participants had minimal stress, 164 (36.4\%) had mild stress, $142(31.6 \%)$ had moderate stress and 103 $(22.9 \%)$ had severe stress. Out of the 73 hypertensive participants, $2(2.7 \%)$ participants had minimal stress, 14 (19.2\%) had mild stress, 29 (39.7\%) had moderate stress and $28(38.4 \%)$ had severe stress. The association between stress and hypertension was found to be statistically significant.

Table 4: Association between stress and hypertension among study population.

\begin{tabular}{|c|c|c|c|c|}
\hline Stress & Hypertensive & Normotensive & Total & p-value \\
\hline Minimal (0 to 8) & $02(2.7 \%)$ & $39(10.3 \%)$ & $41(9.1 \%)$ & \multirow{5}{*}{$\begin{array}{l}X^{2}=21.961 \\
\text { d.f. }=3 \\
\text { p }<0.0001\end{array}$} \\
\hline Mild (9 to 14$)$ & $14(19.2 \%)$ & $150(39.8 \%)$ & $164(36.4 \%)$ & \\
\hline Moderate (15 to $\mathbf{2 1})$ & $29(39.7 \%)$ & $113(30.0 \%)$ & $142(31.6 \%)$ & \\
\hline Severe (22 to 30 ) & $28(38.4 \%)$ & $75(19.9 \%)$ & $103(22.9 \%)$ & \\
\hline Total & $73(100 \%)$ & $377(100 \%)$ & $450(100 \%)$ & \\
\hline
\end{tabular}

\section{DISCUSSION}

Amongst 450 study subjects, 309 (68.7\%) were female and $141(31.3 \%)$ were male. Among 450 participants, 73 (16.2\%) participants were hypertensive and $377(83.8 \%)$ particpants were normotensive. So the prevalence of hypertension in this study was $16.2 \%$ and out of the 73 hypertensive participants, $64(87.7 \%)$ particpants had stage I hypertension and 9 (12.3\%) participants had stage II hypertension.

Similar prevalence was found in a study among adults residing in an urban area of North India (overall prevalence of hypertension was $14.4 \% .9 .5 \%$ had stage I hypertension, $4.9 \%$ had stage II hypertension, and $11.1 \%$ had pre-hypertension range). ${ }^{7}$ While in a study the prevalence was high i.e. $29.3 \%$. This difference could be because of inclusion of higher age group in that study (25-64 years). ${ }^{8}$

In this study, out of the 450 participants $41(9.1 \%)$ participants had minimal stress, $164(36.4 \%)$ had mild stress, $142(31.6 \%)$ had moderate stress and 103 (22.9\%) had severe stress. Out of the 73 hypertensive participants, $2(2.7 \%)$ participants had minimal stress, 14 (19.2\%) had mild stress, $29(39.7 \%)$ had moderate stress and 28 $(38.4 \%)$ had severe stress. It was observed that more hypertensive cases were seen in particpants with higher level of stress and this association was statistically significant $(\mathrm{p}<0.0001)$.

Similar results were seen in a study among the residents of Pune where relative risk of developing hypertension in those who had stress was higher. ${ }^{9}$ But in a study among the Ghanaians in Amsterdam, it was concluded that there is no association between psychological stress and hypertension, this difference could be due to difference in geographical area, also this study concentrated only on recently migrated population while present study is urban area based study which included everyone staying in the area irrespective of their place of origin. ${ }^{10}$ 


\section{Limitations}

This is a cross sectional study, follow up study would give more detailed information. Age group is limited to 20 to 40 years in this study, study of other age groups can yield better picture of stress and hypertension.

\section{CONCLUSION}

Findings of the study concluded that the high level of stress was associated with increased risk of hypertension. Severe stress is associated with development of hypertension. Special attention should be given to increase the awareness about stress, its related complications and prevention and control measures

\section{ACKNOWLEDGEMENTS}

Authors would like to express their thankful regards to Dr. S. R. Suryawanshi, Professor \& Head, Department of Community Medicine, Dr.Yasmeen Kazi, Dr. Anita Shenoy, Dr. Armity for their moral support and suggestions. I gratefully acknowledge the necessary help provided by the staff of Urban Health Center, Shivaji Nagar, for their unconditional support. I am highly indebted to all the people in the study area without whose co- operation, this work would not have been possible.

Funding: No funding sources

Conflict of interest: None declared

Ethical approval: The study was approved by the Institutional Ethics Committee

\section{REFERENCES}

1. Widmaier EP, Raff H, Strang K: Vander's Human Physiology: The Mechanisms of Body Function. 2006, New York: McGraw-Hill international edition 10. 2006.

2. Rutledge T, Hogan BE. A quantitative review of prospective evidence linking psychological factors with hypertension development. Psychosom Med. 2002;64:758-66.
3. Vaillant GE, Gerber PD. Natural history of male psychological health, XIII: Who develops high blood pressure and who responds to treatment? Am J Psychiatry. 1996;153(7 Suppl):24-9.

4. Sparrenberger F, Cichelero FT, Ascoli AM, Fonseca FP, Weiss G, Berwanger O, Fuchs SC, Moreira LB, Fuchs FD. Does psychosocial stress cause hypertension? A systematic review of observational studies. J Hum Hypertens. 2009;23:12-9.

5. Park K. Textbook of preventive and social medicines. Epidemiology of chronic noncommunicable diseases and conditions. 23rd ed. Jabalpur. M/s Banarsidas Bhanot publishers; 2015:372-400.

6. Stress and its consideration: http://www.activeaims.biz/stressed-quetionaire (Last accessed on 25th July 2014).

7. Ahmad S. Prevalence and risk factors of hypertension, among adults residing in an urban area of North India. Int $\mathbf{J}$ Pure App Biosci. 2015;3(2):338-44.

8. Prabakaran J, Vijayalakshmi N, VenkataRao E. Prevalence of hypertension among urban adult population of 25-64 years of Nellore. Int J Res Dev Health. 2013;1:2-5.

9. Deswal BS, Satyamoorthy TS, Dutta PK, Ganguly SS. An epidemiologicai study of hypertension among residents in Pune. Indian $\mathbf{J}$ Community Medicine. 1991;16(1): 21-2.

10. Agyei B, Nicolaou M, Boateng L, Dijkshoorn H, Born B, Agyemang C. Relationship between psychological stress and hypertension among Ghanaians in Amsterdam, the Netherlands- the GHAIA study. BMC public health. 2014;14:692-5.

Cite this article as: Tadvi AY, Bandi JR. An epidemiological cross-sectional study to assess the level of stress and its association with hypertension in young adult population of age group 20 to 40 years in an urban slum of Mumbai, Maharashtra, India. Int J Community Med Public Health 2017;4:348-51. 